\title{
AS BIOGRAFIAS E AS FOTOGRAFIAS NA APRENDIZAGEM DA HISTÓRIA - AS LITERACIAS "VIAJANDO ATRAVÉS DA CARNE"
}

\author{
Maria do Céu de Melo \\ Instituto de Educação - Universidade do Minho \\ Margarida Durães \\ Instituto de Ciências Sociais - Universidade do Minho
}

\begin{abstract}
Resumo
Este texto pretende apresentar algumas reflexões sobre o modo de questionar as biografias e as fotobiografias como fontes e a sua relevância para a aprendizagem da História. Ele foi gerado a propósito de um trabalho proposto aos alunos do curso de História da Universidade do Minho, na disciplina - Atelier da História / História Contemporânea, orientado pela segunda autora (2009). A tarefa era a leitura e análise crítica dos livros: O século XX do rei d. Carlos - Fotobiografia (Vieira, 2008) e a biografia de D. Manuel II (Proença, 2008) $^{* *}$ como fontes históricas. Ele contemplará também uma reflexão sobre os discursos dos autores publicitados na mídia sobre o processo de construção das suas obras e a sua utilidade pedagógica.
\end{abstract}

\section{Palavras-chave}

Biografias $\bullet$ fotografias $\bullet$ história $\bullet$ aprendizagem.

\section{Correspondência}

Instituto de Educação - Universidade do Minho

Campus de Gualtar

4710-057 - Braga - Portugal

Maria do Céu de Melo:

E-mail: mmelo@ie.uminho.pt

Margarida Durães:

E-mail: margaridad@ics.uminho.pt

* A produção deste texto insere-se num conjunto de estudos - "Discursos e práticas na construção da literacia (visual) histórica" (coordenação de Maria do Céu de Melo), inscrita no Grupo de investigação: Literacias e "Práticas e discursos em contextos educativos" (coordenação de Maria Lourdes Dionísio), Centro de Investigação em Educação/Universidade do Minho, Portugal.

** Os últimos reis de Portugal; Implantação da República, 1910. 


\title{
BIOGRAPHIES AND PHOTOS IN HISTORY LEARNING - LITERACIES “TRAVELLING THROUGH THE FLESH"*
}

\author{
Maria do Céu de Melo \\ Instituto de Educação - Universidade do Minho \\ Margarida Durães \\ Instituto de Ciências Sociais - Universidade do Minho
}

\begin{abstract}
This text intends to present some reflections on a possible procedure to historical inquiring guide of biographies and photo-biographies as historical sources, and to discuss their relevance to History learning. It was generated to the purpose of students' essays for the Degree of History /Workshop of Contemporary History, oriented by the second author. The assignment was to write a critical analysis of the D. Manuel II's biography (Proença, 2008 ${ }^{* *}$ ), and the photo-biography King d. Carlos's XX century (Vieira, 2008) as secondary historical sources. It also reflects upon authors' public speeches about their process of writing and their pedagogical usefulness.
\end{abstract}

\section{Keywords}

Biographies $\bullet$ photographies $\bullet$ history $\bullet$ learning.

\section{Contact}

Instituto de Educação - Universidade do Minho

Campus de Gualtar

4710-057 - Braga - Portugal

Maria do Céu de Melo:

E-mail:mmelo@ie.uminho.pt

Margarida Durães:

E-mail: margaridad@ics.uminho.pt

* The production of this text is part of a set of studies "Discourses and practices in construction of literacia (visual) historical" and "Practices and discourses in educational contexts (coord. Maria de Lourdes Dionisio), Centro de Investigação em Educação, Universidade do Minho, Portugal.

** The last kings of Portugal; Deployment of Republica, 1910. 


\section{Introdução}

Ao falar de biografias e de fotografias veio até nós o poema "Retrato de família” de Carlos Drummond de Andrade ${ }^{1}$ do qual retiraremos alguns excertos:

Este retrato de família está um tanto empoeirado. (...) A avó ficou lisa, amarela, sem memórias da monarquia. Os meninos, como estão mudados. (...) O jardim tornou-se fantástico. As flores são placas cinzentas. E a areia, sob pés extintos, é um oceano de névoa. No semicírculo de cadeiras nota-se certo movimento. As crianças trocam de lugar, mas sem barulho: é um retrato. Vinte anos é um grande tempo. Modela qualquer imagem. Se uma figura vai murchando, outra, sorrindo, se propõe. Esses estranhos assentados, meus parentes? Não acredito. São visitas se divertindo numa sala que se abre pouco. Ficaram traços da família perdidos no jeito dos corpos. (...) A moldura deste retrato em vão prende suas personagens. Estão ali voluntariamente, saberiam - se preciso - voar. Poderiam desaparecer no claro-escuro do salão, ir morar no fundo de móveis ou no bolso de velhos coletes. (...) Quem sabe a malícia das coisas, quando a matéria se aborrece? O retrato não me responde, ele me fita e se contempla nos meus olhos empoeirados. E no cristal se multiplicam os parentes mortos e vivos. Já não distingo os que se foram dos que restaram. Percebo apenas a estranha ideia de família viajando através da carne.

“A areia, sob os pés extintos, é um oceano de névoa" exige aos historiadores um navegar laborioso que, do seu mister, reconhecem a produção de narrativas interpretativas provisórias e perspectivadas, norteadas pelo uso das metodologias de investigação historiográfica. Os professores, por seu lado, reconhecem que os alunos, na sua tentativa de compreender o passado, trazem consigo o seu conhecimento histórico, composto por uma teia de conhecimentos oriundos do ensino formal (conhecimentos prévios) organizados em quadros frequentemente de natureza sedimentar e não metamórfico como seria desejável (Lee, 1991; Shemilt, 2000), e de generalizações substantivas tácitas (Melo, 2009) sobre o comportamento dos homens, as suas instituições, crenças e valores. Os alunos utilizam, assim, uma rede de interpretações e compreensões a partir das suas perguntas e da análise das evidências, das narrativas históricas que ouvem, leem ou que vão construindo, devendo, pois, ser confrontados com múltiplas fontes de informação histórica (fontes primárias: verbais, iconográficas, sonoras e multimodais; fontes secundárias: historiográficas, mediáticas...). Compreender o passado é, pois, um

\footnotetext{
Esta memória foi despoletada pela audição deste poema lido por Júnia Sales na sua comunicação Memória, patrimônio e ensino da História durante o VII Encontro Nacional Perspectivas do ensino da História. Universidade Federal de Uberlândia, Minas Gerais, Brasil. Obrigada. Este poema perdeu a sua forma gráfica, tendo sido respeitada a sua pontuação (V. Referências bibliográficas: ANDRADE, 2001).
} 
ato de construção, vivido diferentemente pelos atores históricos, historiadores, professores e alunos, e que vai variando ao longo dos seus contextos históricos de recepção e produção, querendo todos "viajar através da carne" do que está "dito e não dito" nas fontes.

Se aceitarmos esta premissa de atribuição de importância e relevância substantiva ao tutear das fontes, estaremos a defender a discussão deliberativa como um método/estratégia de aprendizagem, já que ela cria condições para que os alunos possam compreender e avaliar a credibilidade das fontes e a informação que apresentam. Daí que possa ser legítimo ver nas palavras do poeta "Já não distingo os que se foram dos que restaram", um apelo para que os alunos tenham crescentemente a consciência de que ideias tácitas e julgamentos contemporâneos devem estar ausentes quanto à interpretação e à contextualização das fontes (Melo, 2009).

O chegar a bom porto neste "oceano de névoa" para os historiadores e educadores históricos sustenta-se na prática da discussão deliberativa que tem como norte criar um consenso sobre os sentidos dos textos, ${ }^{2}$ e que inclui comumente três dimensões que, de acordo com a natureza/linguagem das fontes, são mais ou menos relevantes no seu questionamento histórico.

A primeira, a heurística da fonte, inclui procedimentos prévios à leitura e compreensão do documento centrando-se na natureza da fonte, o seu autor e o contexto de produção. A segunda, a corroboração heurística, contempla o estabelecimento de relações de complementaridade/confronto com outras fontes. A terceira, a contextualização, versa sobre a análise e a explicação do quadro temporal e suas condições históricas, e ou a comparação com outras condições/ situações em outras partes do mundo no mesmo "tempo". É possível pensar num trajeto que se inicia com um momento que cobre a identificação da natureza da fonte (temas e linguagens específicas: jurídico e legislativo, discurso político / teológico, relatos de viagem, cartas, censos, registros paroquiais, doações, testamentos, biografias, fotografias, quadros, cartazes...). Esta remete-nos para a sua autoria (pessoa pública institucional/privadas) e o contexto espaço-temporal de produção, obrigando-nos a pensar nos vínculos, grau de compromisso, aspectos significativos da sua vida privada (objetivos e intenções), e até da sua autoridade no assunto ou situação que aborda. Em muitos casos, é de questionar a audiência esperada das fontes (secreto, divulgação, propaganda, consumo, divertimento etc.) que determina necessariamente a sua natureza (linguagem e tipo de discurso e

2 O termo texto refere-se ao conteúdo substantivo explícito ou implícito que o leitor constrói a partir da leitura de qualquer fonte, seja ela verbal, escrita ou oral, iconográfica, sonora ou multimodal. 
respectivas estratégias). Por fim, é de referir que, no caso da fonte historiográfica, é importante considerar a representatividade do texto no pensamento do historiador, o paradigma/escola em que se insere, e identificar o grau de compromisso e ou distanciação que ele assume face ao tópico em estudo.

Um momento seguinte cobre a análise do conteúdo substantivo da fonte procurando informação sobre pessoas, acontecimentos, um quadro de referência mental (ideias, valores, crenças) de acordo com a sua contextualização específica temporal e espacial, estabelecendo relações com outras fontes e, se adequado, comparando com os contextos locais, regionais, nacionais e mundiais. Esta análise permite a identificação de elementos que clarifiquem causas, consequências, rupturas e persistências, os motivos e condições que nortearam os atos individuais e ou institucionais etc. São estes elementos que sustentarão a construção da explicação narrativa. "Quem sabe a malícia das coisas, quando a matéria se aborrece?" pode ser uma pergunta avisada que nos alerta para a armadilha de transpor para um discurso necessariamente sintético a complexidade do questionamento histórico.

\section{A biografia e a aprendizagem da História}

Ao ler e analisar a biografia histórica como texto construído e sustentado por fontes primárias, poder-se-ão colocar algumas perguntas orientadoras desses procedimentos. Muitas das respostas serão facilmente encontradas, outras estão mais implícitas exigindo uma análise mais minuciosa e inferencial.

Em primeiro lugar, é de considerar algumas condições prévias à escrita da biografia. É significativo saber se a obra foi ou não uma encomenda, e como tal, se ocorreu a priori algum tipo de limites ou constrangimentos, e se o públicoalvo é especializado ou generalista. Ainda neste momento inicial do processo heurístico, é de caracterizar o perfil profissional do autor, tentando determinar as suas intenções frequentemente determinadas pelos quadros e opções epistemológicos e historiográficos e se ocorre ou não a presença de marcas ideológicas. É de considerar também se estão explicitadas evidências da consulta de fontes primárias e secundárias de natureza diversa, se elas apresentam pontos de vista diferentes, e se existem critérios claros de relevância histórica que expliquem a presença/ausência de certos atores e acontecimentos.

Um segundo conjunto de perguntas cobrirá o conteúdo substantivo histórico da narrativa que versa sobre a apresentação de um quadro histórico do contexto local, regional, nacional, internacional onde se moveu o ator histórico eleito, permitindo uma compreensão integrada entre a dimensão da sua vida privada e a pública e a mais institucional. Este quadro deverá adotar uma natureza me- 
tamórfica integrando sempre que relevante as esferas do econômico, político, social, mental, religioso etc.

Sendo a biografia histórica um gênero misto, outros itens podem ser considerados na sua leitura crítica, os quais irão permitir ou obstaculizar que o leitor estabeleça uma empatia histórica com a história e o contexto de vida do biografado: 1) Coerência/conectividade: Este item questiona em que medida a sequência das ideias ou acontecimentos torna explícita a natureza das relações que teceram entre si, assim como com os tipos de atores (individuais /instituições) neles implicados; 2) Legibilidade: Este item releva e/ou confirma se o autor contemplou na sua escrita um certo tipo de leitor (público-alvo) e o contexto em que essa leitura pode ocorrer (informal, escolar etc.); 3) Voz: Alguns autores referem este item, pois reconhecem que muitas biografias apresentam uma "história sem corpo e muda" em que raramente estão presentes as reações aos atos do biografado, adotando um estilo impessoal e de uma limitada riqueza literária (uso de figuras de estilo). Ainda neste item, poder-se-á contemplar a presença ou ausência de expressões coloquiais e ou mesmo citações de diálogos; 4) Motivação: Este item interroga se o texto provoca e mantém o interesse dos leitores, apresentando assuntos e pormenores que sejam novidade e surpreendentes, ou que suscitem conflitos cognitivos, estéticos, morais etc., ou o aparecimento de perguntas, hipóteses, comentários e ou mesmo juízos de valor; 5) Reflexão: Este centra-se na possibilidade da biografia gerar uma reflexão sobre o passado e sobre o presente.

Schick e Hurren (2003), ao defenderam o uso das biografias na aprendizagem da disciplina de Estudos Sociais (EUA), colocam as seguintes perguntas que vão ao encontro das nossas propostas: Como é que estes relatos refletem os acontecimentos? Qual é a relação entre as vidas das pessoas e as "histórias" que nos são contadas? Que tipo de conhecimento confirma ou desafia o ponto de vista dominante expresso no livro? O que é que não foi dito? Como é que estes silêncios possibilitam a criação de modos de pensar (im)possíveis acerca do ator visado ou de certos grupos sociais e as suas experiências?

A defesa deste tipo de questionamento quanto à leitura de uma biografia parte da assunção de que qualquer saber se organiza tendo por base uma estrutura, que ajuda os leitores a compreendê-lo (e organizá-lo) enquanto o frui. Não é de desvalorizar o fato de os leitores terem, ou criarem, certas expectativas sobre o modo como certos tipos de textos estão organizados. Mesmo as crianças mais novas conhecem ou reconhecem, por exemplo, a estrutura narrativa de uma história. Estudos têm provado que a compreensão de uma narrativa é afetada se um destes elementos (momentos) é omisso, ou se são apresentados de uma 
forma (para eles) arbitrária. Por fim, essa estrutura permite ao leitor estabelecer relações dentro da própria informação, e integrá-la naquilo que previamente já "sabe", facilitando a (re)construção de um novo conhecimento que integre o que acabou de ler.

Lopes \& Melo (2004), Melo \& Durães (2004), Durães \& Melo (2005) desenvolveram estudos com estudantes universitários usando este tipo de textos, sendo possível apresentar algumas conclusões:

- Os alunos e os professores desenvolveram uma sensibilidade ao texto escrito historiográfico e literário, o reconhecimento das especificidades da sua escrita e leitura enquanto fontes históricas;

- Existe uma tendência entre os professores de História para considerar o texto escrito apenas como um contentor de informação objetiva (fatos e acontecimentos) esquecendo a sua natureza enquanto fonte histórica (primária ou secundária);

- A necessidade dos professores adquirirem uma formação em análise textual e sócio-semiótica das linguagens artísticas escritas, cinematográficas (e outras multimodais), icônicas e musicais, e de objetos; e

- A defesa de um ensino (e investigação) interdisciplinar incluindo sujeitos e contributos da literatura (língua materna/linguística) e da história.

A leitura crítica de biografias históricas permite que os alunos compreendam que o contexto social, político e econômico nacional e internacional são partes integrantes da vida do ator histórico sobre o qual leram, e que a vida pessoal se desenrola sempre em circunstâncias particulares num movimento de co-construção. Ela permite o questionamento de estereótipos e as narrativas tendenciosas ou oficiais, criando condições para uma atitude de empatia histórica despida de ideias tácitas (Melo, 2009).

\section{As fotografias e a aprendizagem da História}

Ao questionamento histórico de fotografias devem subjazer os seguintes pressupostos. Em primeiro lugar, elas são apenas construções e não, como comumente pensado, representações da realidade já que adotam uma autoria e intenções privadas, sociais, políticas, econômicas e estéticas específicas, por vezes explícitas, outras implícitas. Em segundo, é de considerar que elas são reconstruídas pelos leitores que negociam os sentidos na interação que tecem no processo de leitura e interpretação. 
Perkins (1994, p. 37) defende que olhar e pensar sobre imagens envolve colocar perguntas a nós próprios que foquem as características específicas da obra, descrever o que vemos (desde o tema às suas qualidades formais) e interpretar o que vemos, ou seja, "ao olharmos mais tempo e crescentemente de uma maneira mais refinada e sistematizada ficamos a saber o que não vimos no início". Sontag (1977), no seu famoso ensaio "On photography”, afirma "Na América, o fotógrafo não é simplesmente a pessoa que registra o passado, mas inventa-o". Esta afirmação alerta-nos para a necessidade de uma leitura crítica das fotografias cruzando-as com outras fontes de natureza diversa procedendo ao exercício da corroboração histórica.

Knoblauch et al. (2008) denuncia também que para muitos dos analistas de fotografias "a referência ao contexto da informação visual fica pouco clara. Onde ela foi situada, como foi construída, e como está embebida no contexto da ação, estão frequentemente fora do seu questionamento (...) Isto exemplifica as dificuldades em estabelecer as fronteiras entre a produção e a análise da informação visual". Estes mesmos investigadores defendem que "'Olhar para' significa 'ser enquadrado por', e isso implica que o criador deve ser considerado como sendo um leitor. Para as ciências sociais, proporcionam-nos não apenas insights pessoais, mas também um registo pessoal de relações espaciais e sociais”.

Próximo das nossas preocupações reconhece-se assim que ela pode ser objeto de técnicas de manipulação, das quais nos referiremos às que mais importam quando olhamos para as fotografias como fontes históricas. A primeira "retocar" tem como objetivo fazer desaparecer certos elementos presentes. Um dos exemplos mais famosos é a fotografia de Lênin no Teatro de Bolshoi (1920) que está acompanhado de Trotsky. Sete anos mais tarde, após a luta que ocorreu dentro do partido, a sua figura desaparece. Outra, que parece de natureza meramente técnica "isolar um plano" é fruto do processo de difusão e vulgarização de uma fotografia, e tem como intenção focalizar o olhar (os sentimentos) em um plano, descontextualizando-o das suas condições históricas (Marques, 2006). É o caso da famosa fotografia "Mãe migrante" que frequentemente aparece apenas com o seu bebê ao colo, (Dorothea Lange, 1936) quando na verdade inclui outros elementos: outros filhos de idades diversas, uma tenda provisória encostada a um carro à beira da estrada (Grande Depressão, EUA)... Com o desenvolvimento das técnicas digitais, podemos falar do uso mais frequente de estratégias de manipulação, como a inserção de detalhes (características faciais, cor), a fotomontagem (unir imagens de modo a estabelecer uma relação ou criar uma nova imagem), e/ou a falsa captação (falsificação intencional do contexto de modo a distorcer o sentido). 
Werner (2002), Burke (2001) e Wineburg (1991) apelam, pois, para a necessidade dos alunos não apenas aprenderem a ler as fotografias como a revisitá-las como fontes históricas. Werner (op. cit.) identifica sete tipos de estratégias que podem ser adotadas: a). Instrumental (como fontes de informação), b) Narrativa (focalização na "história"); c) Icônica (identificação dos problemas e dos valores que ela representa); d) Editorial (inferência do julgamento do artista sobre o tópico da foto); e) Indicativa: (inferência das condições sociais expressas na foto); f) Oposição (crítica da "história" e a posição do observador; g) Reflexiva (autoavaliação da interpretação e apreciação da imagem).

No caso específico do contexto que gerou este texto, advogaram-se alguns dos procedimentos do questionamento histórico frequentemente utilizado para as fontes verbais escritas, tendo sido apresentado um guia de análise. É de relevar que é uma proposta generalista, sendo necessário que cada professor a adapte de acordo com a natureza das fotografias e, claro, com as suas intenções pedagógicas particulares.

O primeiro grupo de perguntas orientadoras atém-se à heurística da fonte, que se inicia com a identificação do autor e sua caracterização social, política ou religiosa, a datação da sua criação e, se estivermos perante uma reprodução, saber de onde ela foi retirada. Por vezes, o conhecimento do seu título poderá trazer contributos para a sua compreensão dependendo da sua relevância esclarecedora ou por poder induzir a uma determinada leitura e interpretação. Ainda neste grupo são de questionar as intenções do fotógrafo procurando respostas às seguintes perguntas: O que terá feito interessá-lo pelo assunto que ela aborda? Para quem o autor fez esta fotografia? Foi espontânea ou uma encomenda? Trata-se de um flagrante ou de um retrato no qual as pessoas posam? Haveria uma audiência intencional? O que é que ele quis expressar? Com alunos mais velhos, e/ou os que tenham conhecimentos de fotografia, poder-se-ão colocar algumas perguntas que focam a sua natureza técnica que podem contribuir para a sua heurística: $\mathrm{O}$ que foi incluído no enquadramento da foto (vários planos)? O que foi excluído e por que? Qual é o efeito da luz? Resumindo, como é que certos aspectos técnicos induzem ou afetam as ideias e os sentimentos do fruidor?

Um segundo grupo de perguntas centra-se na leitura e interpretação do texto que a foto propõe explícita ou implicitamente. Estas dependerão do tipo de foto, tema, intenção do professor, idade dos alunos etc. Assim, eis alguns exemplos: Qual é o $1^{\circ}$ elemento/objeto/pessoa que lhe chama a atenção? Que outros elementos ou áreas da foto podem despertar o interesse? Por que? Quem são as pessoas e o que estão a fazer? Que sons, cheiros, temperatura poder-se-ão inferir da foto? 
O que a foto nos diz sobre as condições pessoais, sociais, econômicas, políticas, religiosas, científicas do "tempo" retratado?

Um terceiro grupo tem como objetivo o exercício da corroboração heurística que gerará evidências que permitam uma contextualização histórica sustentada e coerente, ou seja, a presença de fontes que forneçam respostas críveis ou sustentem as respostas encontradas: Encontra-se outro tipo de documentos que abordem o mesmo assunto? Quais são as diferenças? Que problemas e sua natureza se encontram neste processo? Que evidências apresentam para a integração da fotografia e do seu texto no contexto histórico local, nacional e mundial?

As respostas a estas perguntas e outras devem ser justificadas, permitindo assim ao professor caracterizar o tipo de argumento/raciocínios dos alunos que são essenciais para a definição da sua literacia visual histórica.

\section{As vozes dos autores da biografia de d. Manuel Il e da fotobiografia de d. Carlos}

Foi proposta aos alunos a pesquisa de possíveis intervenções públicas ${ }^{3}$ feitas pelos autores. Quando da publicação destes dois livros, já os consideramos como fontes de informação relevantes para os alunos envolvidos no ateliê acederem ao seu processo de criação, particularmente a sua metodologia. Encontramos apenas umas breves entradas tendo o formato de respostas (ou citações) dadas a entrevistas (ver Referências bibliográficas: sites-entrevistas). É de realçar a diferença dos textos colocados on-line, particularmente as perguntas colocadas, umas explícitas, outras implícitas, fato que determinou a natureza, o âmbito e a profundidade das respostas. Ao analisá-las, criamos algumas categorias de modo a permitir alguns comentários sobre se as intervenções poderiam ou não cumprir a função acima referida.

Cândida Proença, autora da biografia de d. Manuel II, muito sucintamente apresenta alguns comentários sobre o seu trabalho. Eis o retrato que nos oferece do homem:

D. Manuel II era um moderador, cauteloso sem dúvida, e profundamente preso ao juramento que fizeram à Carta Constitucional, a 6 de maio de 1908, quando assumiu a coroa.

(...) não era o tonto que a propaganda republicana pretendeu fazer dele.

A sua curta ação política como soberano, de 1908 a 1910 (...) demonstra preocupação com o país (...). Estudava as pastas até altas horas da noite e era atento à situação política.

As citações dos criadores da biografia e da fotobiografia foram retiradas dos sites que se encontram referenciados nas referências bibliográficas. 
D. Manuel tinha um grande amor a tudo o que era português e teve sempre em primeiro plano os interesses patrióticos e dos portugueses, e não os seus.

Quanto ao seu processo de trabalho, as suas palavras apenas referem o tempo de criação que esta biografia exigiu (seis meses) e que, para tal, utilizou dois fundos documentais inéditos, o espólio de d. Manuel II e o que se encontra depositado na Associação Cultural da Casa de Sabugosa e S. Lourenço. Sobre estes afirmou:

[Estes dois núcleos documentais] deram achegas muito importantes para compreender melhor não só a personalidade de d. Manuel como os seus pais e várias personalidades da época. ...são muito interessantes as cartas trocadas entre o rei e o marquês de Sobral, e também com Henrique de Paiva Couceiro, que tentou reinstaurar a monarquia.

Por fim, fala de novos dados históricos que o seu livro apresenta:

Estes documentos dão, por exemplo, novas pistas relativamente ao Pacto de Dover que estabelece a pretensão ao trono [assinado em 1912 pelos dois ramos da família de Bragança].

O rei, relativamente a Couceiro, não o apoiou abertamente, pois foi sempre cauteloso. Defendia antes uma campanha de esclarecimento que naturalmente faria desejar o regresso da monarquia. Defendia também que os monárquicos deviam ir conquistando lugares no Parlamento e de destaque na sociedade.

[Esta biografia procura] ser esclarecedora relativamente à ideia feita do monarca pela propaganda republicana, traz novos dados da sua atitude política durante o exílio em Inglaterra, e a sua ação na Cruz Vermelha Internacional.

Mesmo reiterando vários condicionalismos que podem ter existido na preparação do guia pelo entrevistador, poder-se-á afirmar que estas palavras não elucidam o seu processo de trabalho, particularmente sobre as suas opções e/ou os problemas encontrados. Assim sendo, os alunos envolvidos no processo heurístico não puderam contar com a voz da autora, tendo então que fazer inferências ou mesmo levantar hipóteses sobre esta dimensão ao responderem a algumas das perguntas do guia proposto por nós.

Já as palavras proferidas por Joaquim Vieira, o autor da fotobiografia, foram muito mais esclarecedoras. O homem (o rei) é-nos assim descrito:

Esta fotobiografia devolve uma imagem um pouco diferente: um rei que se desdobra em atividades, que tem características de príncipe renascentista, era pintor, cientista, investigador, tinha uma vocação para o tênis, para a caça, para o automobilismo, para as touradas e era agricultor (ganha prêmios como agricultor com talento). Todas estas facetas descrevem uma personalidade diferente da tal imagem tradicional e que nos fazem crer 
que seria um rei que, noutras circunstâncias, teria uma imagem positiva perante o povo português, mas teve o azar de nascer naquelas circunstâncias e, fosse ele ou fosse outro, estaria sempre condenado - o momento histórico a isso levava.

[Qual é imagem-chave para o perfil de d. Carlos?] Talvez uma das imagens em que ele está fotografado em Vila Viçosa com toda uma série de amigos e de familiares à volta. Mostra uma componente lúdica que ele tinha da vida, gostava talvez mais de se divertir do que de ser rei. Mostra uma certa inconsciência, esse lado frívolo da vida dele... é claro que há aspectos mais importantes como a sua atividade diplomática, mas como estão entre esse amigos alguns diplomatas talvez analisando cada um das pessoas que estão presentes nesses retratos acabemos por concluir que vida de d. Carlos se resumia um bocado aquele universo.

Joaquim Vieira é prolífero quanto aos procedimentos metodológicos por si adotados. Começa por nos alertar para uma certa "sacralização" da imagem:

Seguimos aquele provérbio de que uma imagem vale mil palavras... mas não é tanto assim. É evidente que a palavra tem um poder muito forte e há descrições através da palavra que até deixam muita mais à imaginação. Mas não estamos a falar de ficção. Estamos a falar de trabalhos ensaísticos, de alguma maneira documentais, de divulgação, históricos. $\mathrm{O}$ que acontece é que o século XX foi o século das imagens. Houve uma explosão na forma de comunicação ao público e às grandes massas através da imagem.

De seguida, desenvolve o seu alerta esclarecendo o seu principal pressuposto metodológico:

A imagem acaba por funcionar como uma fonte, como testemunho histórico - como fonte documental. Antigamente para se contar os acontecimentos confiava-se sobretudo no texto, é claro que havia imagens, havia pintura, havia retratos, havia desenhos, mas havia sempre na criação dessas imagens um fator de subjetividade: o autor retratava à sua maneira. Com a fotografia e o cinema isso é diferente. Embora o operador de cinema ou o fotógrafo nunca mostrem a realidade no seu todo, sabemos que corresponde a uma coisa visível que aconteceu: tal qual como ocorreu. Eu costumo dizer que isto é como uma casa em que as imagens são os tijolos e o texto é a argamassa. São sempre precisos os dois.

Neste caso, o entrevistador contribuiu para o desvelar das decisões de Vieira, perguntando: "A montagem final de imagens obedece à iconografia reunida ou respeita, no caso de surgirem algumas lacunas, a biografia que existe para além das imagens disponíveis?", e ao que o jornalista respondeu:

Mais uma vez há um compromisso entre uma coisa e a outra. Por um lado definimos em cada volume uma ossatura genérica, aqueles que são os grandes temas relacionados com 
a figura escolhida, as grande etapas - independentemente de haver imagens ou não. Mas dentro dessas grandes áreas podemos abrir subcapítulos, caixas, consoante o tipo de imagens que encontramos. Por exemplo, no D. Carlos, dado que tínhamos muitas pinturas e desenhos, isso acabou por ocupar um certo espaço na biografia dele, se fosse só uma biografia em texto não se daria tanta importância a essas coisas.

Tal como Proença, Vieira esclareceu as fontes utilizadas, referindo a consulta dos arquivos oficiais e particulares (Casa de Bragança) assim como a imprensa estrangeira e livros (alfarrabistas em Paris). Não esqueceu, no entanto, outros tipos mais "invulgares": “... depois existem as coleções particulares, colecionadores de carteiras de fósforos, desenhos humorísticos, jornais, revistas e, às vezes, descobrem-se coisas muito interessantes porque há mais possibilidades de descobrir material inédito com essas fontes". Uma vez mais, e apesar da riqueza das fontes iconográficas, Vieira, retoma o alerta anterior denunciando:

Agora não acredito que seja possível esgotar apenas na imagem toda a informação que é importante dar. Por isso mais uma vez digo que o texto enquanto argamassa deste livro é fundamental. A imagem dá um aspecto parcelar, e a forma como as imagens estão organizadas dá muito daquilo que é o conteúdo do livro, mas diria que é preciso ancorar com o texto.

Compelido uma vez mais por esta questão do entrevistador "Assim como a leitura de um documento escrito implica o decifrar do não-dito, como se chegam às entrelinhas da imagem?", ele alerta para algumas das dimensões heurísticas por nós referidas no guia proposto, nomeadamente, a manipulação e a necessária contextualização:

Tentamos fazer a interpretação das imagens e tentamos ajudar o leitor a situar-se. Tal como existem os textos censurados, também foi feita uma manipulação de imagem e fotomontagens para engrandecer a figura, para criar uma espécie de égide a Salazar [outro dos fotobiografados por Vieira]. É uma questão de avisar o leitor, atenção, isto é manipulado. É claro que uma imagem pode ter sempre mais de uma interpretação, acho que cada pessoa vai ler aquela imagem de uma forma diferente, e vai ver coisas que outra pessoa não viu (...) Queremos é dar a informação às pessoas para elas poderem ler essas imagens de uma forma mais aprofundada, saberem o contexto e saberem o que ela significa.

Por fim, e assumindo o seu duplo papel de jornalista e escritor, esclarece-nos sobre o que chama as fronteiras "difusas":

Como jornalista fiz muitos trabalhos relacionados com a história contemporânea e com o século XX. Há aqui uma fronteira difusa, sendo o jornalista o cronista do quotidiano não fala só sobre aquilo que está a acontecer mas sobre o que aconteceu há relativamente pouco tempo, sobretudo quando há testemunhos vivos e de pessoas ainda vivas. Ganhei 
o gosto pela história contemporânea. (...) Foi um pouco por iniciativa própria... não tinha sequer a pretensão de desenvolver muito esta faceta de historiador mas acabou por acontecer. "Portugal século XX" conciliava o contar (de uma forma jornalística) o que tinha acontecido em cada década. É claro que fui consultando várias fontes históricas, mas há aqui uma componente jornalística que eu nunca perdi.

Termina, salvaguardando o seu estatuto e o seu labor:

...não tenho a pretensão de ser um historiador, embora ache que o trabalho do jornalista é importante para a história e para os historiadores. Ao fazer algumas investigações verifico que quando os historiadores fazem trabalhos sobre a história nos últimos 300/400 anos a primeira coisa que fazem é ir à Biblioteca Nacional verificar os jornais. Essa crônica do quotidiano que é feita pelo jornalista é uma base documental fundamental.

\section{Palauras finais}

Neste momento, é de relembrar que este texto foi desencadeado por uma tarefa feita durante uma unidade curricular intitulada - Atelier da História, em que os alunos do $3^{\circ}$ ano do curso de História tiveram que ler, analisar e comentar criticamente as obras de Proença (2008) e de Vieira (2008).

Considerando a leitura e a avaliação dos trabalhos feita pelas professoras, reconhece-se que ainda existe um longo caminho a percorrer na manipulação de guias de questionamento histórico dos dois tipos de fontes usadas: biografia e a fotobiografia. Sob pena de ser considerada uma generalização abusiva, poderse-á afirmar que lhes tem sido atribuído, respectivamente, uma função de mero entretenimento ou de ilustração.

E, quando outras funções didáticas são propostas, as tarefas que lhes estão anexas não contemplam todas as dimensões que a sua natureza contém enquanto simultaneamente objetos artísticos e fontes primárias /secundárias que apresentam uma narrativa, e ou que sobre elas outras narrativas podem ser construídas pelos seus leitores /fruidores (Melo, 2008, p. 13).

O valorizá-las, integrando-as no quotidiano dos nossos discursos e práticas enquanto docentes e investigadoras, significa a nossa preocupação em compreender os modos como os alunos criam sentidos ao estabelecerem "encontros empáticos" com sujeitos históricos que corporizaram valores, crenças, intenções, sentimentos diferentes dos contemporâneos, sujeitos com um nome, bilhete de identidade, uma "história" e evidências produzidas em "1 $1^{a}$ mão", trazendo a dimensão pessoal e privada ao estudo da História. 


\section{Referências bibliográficas}

ANDRADE, Carlos Drummond de. Antologia poética. Lisboa: Publicações Dom Quixote, 2001.

BURKE, Peter. Eye witnessing: The uses of images as historical evidence. Ithaca, Nova York: Cornell University Press, 2001.

DURÃES, Margarida \& MELO, Maria do Céu. AS NARRATIVAS LITERÁRIAS COMO FONTE HISTÓRICA: “A GUERRA E A PAZ” NAAULA DE HISTÓRIA. In: XXIII SIMPÓSIO NACIONAL DE HISTÓRIA: HISTÓRIA, GUERRA E PAZ. Anais. (CD. ROM). Associação Nacional de História. Londrina: Editorial Média, 2005.

KNOBLAUCH, Hubert et al. Visual analysis. New developments in the interpretative analysis of video and photography]. FÓRUM: QUALITATIVE SOCIAL RESEARCH, 9 (3), art. 14, 2008. Disponível em: http://nbn-resolving.de/ urn:nbn:de:0114-fqs0803148.

LEE, Peter. Historical knowledge and the national curriculum. In: ALDRICH, R. (ed.). History in the national curriculum. Londres: Bedford Way. Institute of Education, University of London, 1991, p. 39-65.

LEVSTIK, Linda \& BARTON, Keith. Doing history. Mahwah, NJ: Lawrence Erlbaum Associates, 2001.

LOPES, José Manuel \& MELO, Maria do Céu. A recepção do texto historiográfico e ficcional: análise de um inquérito, In: MELO, Maria do Céu de \& LOPES, José Manuel (orgs.). Narrativas históricas e ficcionais. Recepção e produção de professores e alunos. Braga: Centro de Investigação em Educação. Universidade do Minho, 2004, p. 11-27.

MARQUES, Isabel. Perguntas às fontes: Um estudo sobre a leitura de fotografias e testemunhos por alunos do $10^{\circ}$ ano de escolaridade. Tese de mestrado em Educação, Supervisão Pedagógica em Ensino da História, Instituto de Educação e Psicologia, Universidade do Minho, 2006.

MELO, Maria do Céu (org.). O conhecimento (tácito) histórico: Polifonia de alunos e professores. Braga: Centro de Investigação em Educação, Instituto de Educação e Psicologia, Universidade do Minho, 2009.

MELO, Maria do Céu (org.). As imagens na aula de História: diálogos e silêncios. Mangualde: Edições Pedago, 2008.

MELO, Maria do Céu \& DURÃES, Margarida. A leitura de romances e a aprendizagem da História contemporânea. In: MELO, Maria do Céu de \& LOPES, José Manuel Lopes (orgs.). Narrativas históricas e ficcionais. Recepção e produção de professores e alunos. Braga: Centro de Investigação em Educação, Universidade do Minho, 2004, p. 59-79.

PERKINS, David. The intelligent eye: Learning to think by looking at art. Santa Monica, CA: The Getty Education Institute for the Arts, 1994. 
PROENÇA, Maria Cândida. D. Manuel II. Lisboa: Editora Temas e Debates /Coleção Biografias Reis de Portugal, 2008.

SANDWEISS, Martha. Image and artifact: The photograph as evidence in the digital age. Journal of American History, 94, junho de 2007, p. 193-202.

SCHICK, C. \& HURREN, W. Reading autobiographies, memoirs, and fictional accounts in the classroom: Is it social studies? Canadian Social Studies, vol. 3 (2), 2003.

SHEMILT, Denis. The caliph's coin. The currency of narrative frameworks in History teaching. In: STEARNS, P., SEIXAS, P. \& WINEBURG, S. (eds.). Knowing teaching \& learning History. Nova York: New York University Press, 2000, p. 83-101.

SONTAG, Susan. On photography. Nova York: Picador U.S.A., 2001.

VIEIRA, Joaquim. O século XX do rei d. Carlos - Fotobiografia. Lisboa: Editora Temas e Debates, 2008.

WERNER, W. Reading visual texts. Theory and research in social education, 30 (3), 2002, p. 401-428.

WINEBURG, Sam. Historical problem solving: A study of the cognitive processes used in the evaluation of documentary and pictorial evidence. Journal of Educational Psychology, 83 (1), 1991, p. 73-87.

\section{Sites}

Entrevistas dadas pelos autores Cândida Proença e Joaquim Vieira

//circulo.claranet.pt/entrevistas/ler.php?id=47

www.gforum.tv/board/1279/228416/nova-biografia-de-d-manuel-ii-revela-um-reiatento-e-cuidadoso-e-nao.html (Agência Lusa)

http://tv1.rtp.pt/noticias/?article $=62877 \&$ visual $=3$ \&layout $=10$

http://diario.iol.pt/sociedade/rei-d-manuel-ii-rei-de-portugal-monarca-historiamonarquia/960181-4071.html 